ISLAMIC BANKING: Jurnal Pemikiran dan Pengembangan Perbankan Syariah, Volume 7 Nomor 2 Edisi Februari 2022

\title{
PENGARUH MANAJEMEN GAP, MODAL, LIKUIDITAS, RISIKO PEMBIAYAAN, TINGKAT EFISIENSI DAN UKURAN BANK (SIZE) TERHADAP NET INTEREST MARGIN PADA BANK SYARIAH MANDIRI, BANK BRI SYARIAH DAN BANK BNI SYARIAH TAHUN 2015-2019
}

\author{
Inna Cikita Mahdatika \\ Magister Sains Ekonomi Islam, Fakultas Ekonomi dan Bisnis, Universitas Airlangga \\ Email: inna.cikita.mahdatika-2019@feb.unair.ac.id
}

Atina Shofawati

Fakultas Ekonomi dan Bisnis, Universitas Airlangga

Email: atina-o@feb.unair.ac.id

\begin{abstract}
Net Interest Margin (NIM) is an indicator of the operational efficiency of a bank which is considered an important instrument used to assess the ability of effectiveness and managerial efficiency in utilizing bank resources and is also very important for controlling bank spending. This study aims to determine the relationship between Gap Management, Capital, Liquidity, Financing Risk, Efficiency Level and Bank Size (Size) on Net Interest Margin (NIM) at Mandiri Sharia Bank, BRI Sharia and BNI Sharia 2015-2019. Using panel data regression support with Random Effect Methods (REM). The results showed that simultaneously all exogenous variables have a significant effect on the endogenous variable Net Interest Margin (NIM). Partially the Gap Management and Liquidity variables have a significant positive effect on Net Interest Margin (NIM). Meanwhile, the variables of Capital and Bank Size have a significant negative effect on Net Interest Margin (NIM). However, the variable financing risk and efficiency level did not have a significant effect on the Net Interest Margin (NIM) at PT. Bank Syariah Mandiri Tbk, PT. Bank BNI Syariah Tbk, PT. BRI Syariah Tbk.
\end{abstract}

Keywords: Gap Management, Capital, Liquidity, Financing Risk, Net Interest Margin.

\begin{abstract}
Abstrak
Net Interest Margin (NIM) merupakan indikator efisiensi operasional suatu bank yang dianggap sebagai instrumen penting yang digunakan untuk menilai kemampuan efektivitas dan efisiensi manajerial dalam memanfaatkan sumber daya bank dan juga sangat penting untuk pengendalian pengeluaran bank. Penelitian ini bertujuan untuk mengetahui hubungan antara Manajemen Gap, Modal, Likuiditas, Risiko Pembiayaan, Tingkat Efisiensi dan Ukuran Bank (Size) terhadap Net Interest Margin (NIM) Pada Bank Syariah Mandiri, Bank BRI Syariah dan BNI Syariah Tahun 2015-2019. Menggunakan dukungan regresi data panel dengan Random Effect Methods (REM) digunakan dalam penelitian ini untuk menguji hubungan variabel eksogen terhadap variabel endogen, baik secara parsial atau simultan. Hasil penelitian menunjukkan bahwa secara simultan semua variabel eksogen berpengaruh signifikan terhadap variabel endogen Net Interest Margin (NIM). Secara parsial variabel Manajemen Gap dan
\end{abstract}


316 Inna Cikita Mahdatika \& Atina Shofawati, PENGARUH MANAJEMEN GAP, MODAL, LIKUIDITAS, RISIKO

Likuiditas berpengaruh positif signifikan terhadap Net Interest Margin (NIM). Sedangkan variabel Modal dan Ukuran Bank berpengaruh negatif signifikan terhadap Net Interest Margin (NIM). Namun variabel risiko pembiayaan dan tingkat efisiensi tidak berpengaruh signifikan terhadap Net Interest Margin (NIM) pada PT. Bank Syariah Mandiri Tbk, PT. Bank BNI Syariah Tbk, PT. BRI Syariah Tbk.

Kata Kunci: Manajemen Gap, Modal, Likuiditas, Risiko Pembiayaan, Net Interest Margin.

\section{Dasar Pemikiran}

Kemajuan perekonomian di dunia saat ini tidak dapat dipisahkan dari dunia perbankan. Peran bank sebagai perantara keuangan membuat roda perekonomian suatu negara tetap berjalan dengan mempertemukan pihak yang membutuhkan dana dengan pihak yang memiliki dana. Dunia perbankan juga tidak bisa dipisahkan dari aspek kebijakan makro khususnya terhubung dengan manajemen aset moneter sebuah negara (Saksonova, 2014). Dalam menjalankan perannya ini bank berusaha untuk mendapatkan pendapatan bunga bersih (Net Interest Margin) sebagai salah satu pendapatan terbesarnya agar tetap bertahan hidup dengan cara mengelola aset-aset produktifnya dengan baik.

Net Interest Margin merupakan salah satu faktor penting yang digunakan untuk mengukur efisiensi bank sebagai perantara yang berkaitan dengan pengelolaan tabungan dan memberikan pinjaman bahkan menjadi aspek mendasar (Fundemental factor) dalam sebuah lembaga intermediasi (Islam \& Nishiyama, 2016). Dalam hal ini, Bank Indonesia secara terus menerus memberikan himbauan terhadap pihak perbankan agar terus meningkatkan fee base income, yaitu pendapatan yang diperoleh dari jasa-jasa bank selain dari selisih bunga. Harapan dari Bank Indonesia agar tingkat Net Interest Margin perbankan Indonesia dapat selevel dengan perbankan negara ASEAN. Net Interest Margin yang terlalu tinggi akan meningkatkan beban masyarakat, namun apabila Net Interest Margin terlalu kecil juga akan berdampak pada berkurangnya profit bank. Hal ini menyebabkan pentingnya keseimbangan dari Net Interest Margin untuk dijaga agar tidak berdampak negatif terhadap kinerja sektor perbankan (Arif, 2018).

Adanya kebijakan dari Otoritas Jasa Keuangan (OJK), bank harus menemukan cara dan strategi yang tepat agar dapat memenuhi kebijakan yang telah ditetapkan. Untuk itu, penting untuk menentukan faktor-faktor yang mengendalikan Net Interest 
ISLAMIC BANKING: Jurnal Pemikiran dan Pengembangan Perbankan Syariah, Volume 7 Nomor 2 Edisi Februari 2022

Margin pada bank Syariah di Indonesia. Karena Net Interest Margin merupakan sebuah indikator efisiensi operasional di bank yang dipertimbangkan sebagai instrumen penting yang digunakan untuk mengevaluasi kemampuan efektifitas manajerial dan efisiensi dalam memanfaatkan sumber daya bank dan juga sangat penting untuk mengendalikan pengeluaran bank. Terdapat beberapa faktor yang dapat mempengaruhi Net Interest Margin antara lain modal, likuiditas, pembiayaan, tingkat efisiensi dan ukuran bank.

Dalam pengelolaan Net Interest Margin, tentunya diperlukan sarana manajemen untuk meminimalisir resiko-resiko yang akan di hadapi oleh bank. Sedangkan yang terjadi dalam laporan keuangan perbankan, terdapat beberapa aset dan liabilitas bank syariah bersifat sensitif terhadap suku bunga. Aset yang tergolong sensitif adalah call money placement, SBPU, SBI, Saham, Obligasi. Sedangkan liabilitas yang bersifat sensitif adalah Giro, tabungan, simpanan berjangka sampai 12 bulan, call money dan SBPU (Riyadi, 2006). Hal ini dapat menimbulkan gap atau kesenjangan antara aset dan liabilitas pada periode yang sama meliputi kesenjangan dalam jumlah dana, suku bunga, jatuh tempo, ataupun perpaduan ketiganya. Adanya kesenjangan aset sensitif terhadap liabilitas sensitif tersebut dapat mempengaruhi pendapatan margin suatu bank syariah. Untuk itu perlu adanya manajemen gap yang bertujuan untuk mempersempit kesenjangan tersebut agar dapat memberikan dampak positif terhadap Net Interest Margin.

Berdasarkan penelitian terdahulu, penelitian ini telah di teliti oleh para peneliti sebelumnya dan mendapat hasil yang berbeda-beda. Dari perbedaan tersebut penulis membuat penelitian lanjutan mengenai pengaruh modal, rasio likuiditas, risiko pembiayaan, tingkat efisiensi dan ukuran bank pada perbankan syariah. Tabel dibawah ini akan menjelaskan kesenjangan dari hasil penelitian terdahulu.

\section{Tabel 1}

\section{Penelitian Terdahulu}

\begin{tabular}{|l|c|c|c|c|c|}
\hline \multicolumn{1}{|c|}{ Peneliti } & EA & NPL & LDR & Bank Size & BOPO \\
\hline Deny Asna & Tidak & Berpengaruh & Berpengaruh & Tidak & Tidak \\
Widyanto, R. Ery & Berpengaruh & Positif & Positif & Berpengaruh & Berpengaruh \\
Wibowo Agung & & & & & \\
\hline
\end{tabular}




\begin{tabular}{|l|c|c|c|c|c|}
\hline $\begin{array}{l}\text { Elizabeth Dewi } \\
\text { Kusumaningrum }\end{array}$ & $\begin{array}{c}\text { Berpengaruh } \\
\text { Positif }\end{array}$ & $\begin{array}{c}\text { Tidak } \\
\text { Berpengaruh }\end{array}$ & - & $\begin{array}{c}\text { Tidak } \\
\text { Berpengaruh }\end{array}$ & $\begin{array}{c}\text { Berpengaruh } \\
\text { Negatif }\end{array}$ \\
\hline $\begin{array}{l}\text { Indah Lestari Dewi } \\
\text { dan Nyoman } \\
\text { Triaryanti }\end{array}$ & Berpengaruh & Berpengaruh & Berpengaruh & Berpengaruh & Berpengaruh \\
Positif & Negatif & Positif & Positif & Positif \\
\hline
\end{tabular}

Sumber: Data diolah.

Berdasarkan kesenjangan hasil penelitian ini maka perlu dilakukan penelitian kembali agar dapat mengimplementasikan keadaan terbaru mengenai perbankan syariah di Indonesia. Dalam penelitian ini juga ditambahkan variabel manajemen gap (kesenjangan antara Rate Sensitive Asset dengan Rate Sensitive Liability) yang mana variabel ini turut menentukan tingkat profitabilitas dari sistem operasional perbankan syariah. Karena pada neraca bank terdapat beberapa pos yang peka terhadap perubahan tingkat bunga. Pos tersebut berada di sisi aset maupun liabilitas. Jika pos tersebut tidak dikelola dengan baik, maka net interest income akan menurun. Maka penting adanya manajemen gap dalam mengelola Net Interest Margin.

Diketahui saat ini ada tiga Bank Syariah yang merupakan anak usaha BUMN yakni PT. Bank Syariah Mandiri Tbk, PT. Bank BNI Syariah Tbk, PT. BRI Syariah Tbk. Terkait rencana Kementrian BUMN untuk melakukan merger untuk ketiga bank syariah tersebut ternyata sudah tertuang dalam road map pengembangan perbankan syariah tahun 2015-2019, yang dirangkum dalam visi "mewujudkan perbankan syariah yang berkontribusi signifikan bagi pertumbuhan ekonomi berkelanjutan, pemerataan pembangunan serta berdaya saing tinggi". Dimana salah satunya, melalui merger tiga bank syariah milik BUMN. Salah satu tujuan utama dari merger ini pastilah peningkatan efisiensi kinerja bank syariah sehingga mampu bersaing dengan bank konvensional, yang pada akhirnya diharapkan mampu meningkatkan pangsa pasar (market share) Bank Syariah. Berdasarkan permasalahan yang sedang terjadi pada ketiga bank syariah yang akan di merger tersebut alasan peneliti menjadikan tiga bank tersebut sebagai obyek dalam penelitian ini untuk mengetahui bagaimana Net Interest Margin dalam ketiga bank syariah milik BUMN dalam proses realisasi terjadinya merger bank syariah nantinya. 
ISLAMIC BANKING: Jurnal Pemikiran dan Pengembangan Perbankan Syariah, Volume 7 Nomor 2 Edisi Februari 2022

Berdasarkan latar belakang di atas, adanya perbedaan hasil penelitian-penelitian terdahulu (research gap) dan fenomena gap, maka perlu dilakukan penelitian lebih lanjut mengenai pengaruh manajemen gap, modal, likuiditas, risiko pembiayaan, tingkat efisiensi dan ukuran bank (size) terhadap Net Interest Margin (NIM) pada Bank Syariah Mandiri, Bank BRI Syariah dan Bank BNI Syariah tahun 2015-2019.

\section{Landasan Teori dan Pengembangan Hipotesis}

Net Interest Margin (NIM). Net Interest Margin (NIM) adalah rasio yang digunakan untuk menunjukkan kemampuan manajemen bank dalam mengelola aktiva produktifnya untuk menghasilkan pendapatan bunga bersih. Net Interest Margin (NIM) digunakan untuk mengukur kemampuan bank dalam menghasilkan pendapatan dari bunga dengan melihat kinerja bank dalam mneyalurkan kredit, dimana semakin besar NIM yang dicapai suatu bank maka akan meningkatkan pendapatan bunga atas aktiva produktif yang dikelola oleh bank yang bersangkutan, sehingga laba bank akan meningkat (Astohar, 2019).

Manajemen Gap. Dalam penelitian (Askarullah, 2017) menjelaskan bahwa gap merupakan perbedaan atau selisih antara aset yang sensitif terhadap suku bunga (Rate Sensitive Asset / RSA) dengan liabilitas yang sensitif terhadap suku bunga (Rate Sensitive Liability / RSL). Sedangkan manajemen gap bertujuan untuk mempersempit lebarnya kesenjangan antara Rate Sensitive Asset (RSA) dengan Rate Sensitive Liability (RSL). Manajemen gap merupakan pengaturan gap yang disebabkan oleh tingkat deegre of sensitivitas dari masing-masing pos aset maupun masing-masing pos liabilitas yang berbeda-beda.

Modal. Modal adalah sekumpulan uang atau barang yang digunakan sebagai dasar pelaksanaan suatu pekerjaan. Modal merupakan faktor yang sangat penting dalam bisnis perbankan karena keberhasilan suatu bank didasarkan bagaimana bank tersebut mampu mengelola modal dengan baik. Untuk mengukur besar atau kecilnya modal diperlukan adanya Capital Adequacy Ratio (CAR), dimana rasio tersebut besarnya modal suatu bank akan berpengaruh pada mampu atau tidaknya suatu bank secara efisien menjalankan kegiatannya. 
320 Inna Cikita Mahdatika \& Atina Shofawati, PENGARUH MANAJEMEN GAP, MODAL, LIKUIDITAS, RISIKO

Likuiditas. Likuiditas merupakan ukuran kemampuan bank untuk membayar kembali seluruh kewajiban lancarnya. Ukuran likuiditas didasarkan pada persediaan yakni FDR (Financing to Deposit Ratio). FDR (Financing to Deposit Ratio) ini menyatakan kemampuan bank dalam membayar penarikan dana yang dilakukan oleh deposan dengan mengandalkan pembiayaan yang diberikan sebagai sumber likuiditasnya. Semakin tinggi rasio FDR tersebut memberikan indikasi rendahnya kemampuan likuiditas yang bersangkutan.

Risiko Pembiayaan. Pembiayaan secara luas berarti pendanaan yang dikeluarkan untuk mendukung investasi yang telah direncanakan. Risiko pembiayaan muncul jika bank tidak bisa memperoleh kembali cicilan pokok dana atau bunga dari pinjaman yang diberikannya atau investasi yang sedang dilakukannya. Pengukuran risiko pembiayaan dapat dilakukan melalui indikator Non Performing Financing (NPF). Non Performing Financing (NPF) adalah perbandingan antara total pembiayaan bermasalah dengan total pembiayaan yang di berikan kepada debitur. Non Performing Financing (NPF) menunjukkan seberapa besar kolektibilitas bank dalam mengumpulkan kembali pembiayaan yang telah disalurkan.

Tingkat Efisiensi. Tingkat efisiensi merupakan salah satu parameter yang sering digunakan untuk mengukur kinerja organisasi. Tujuan dari efisiensi adalah untuk mendapatkan tingkat output yang optimal dengan input yang ada. Tingkat efisiensi merupakan alat ukur rasio keuangan yang sering kali digunakan untuk mengukur kinerja suatu organisasi. Dalam perbankan, rasio yang digunakan untuk mengukur tingkat efisiensi di bank syariah adalah dengan indikator biaya operasional dibandingkan dengan pendapatan operasional (BOPO).

Ukuran Bank (Bank Size). Ukuran bank adalah suatu skala yang dapat mengelompokkan besar kecilnya suatu perusahaan. Ukuran bank dapat diukur dengan melihat total aset, total penjualan, atau total modal. Meningkatnya ukuran perbankan akan meningkatkan biaya operasional bank sehingga secara proses mungkin akan membebani dan berpengaruh negatif terhadap pendapatan Bank (Islam \& Nishiyama, 2016), Namun, semakin besar ukuran Bank, maka efisiensi akan semakin meningkat dan mendorong bank untuk memperbesar usaha sehingga margin yang dihasilkan juga 
ISLAMIC BANKING: Jurnal Pemikiran dan Pengembangan Perbankan Syariah, Volume 7 Nomor 2 Edisi Februari 2022

akan semakin meningkat. Semakin besar ukuran bank yang ditunjukkan dengan kepemilikan aset yang besar. Oleh karena itu, dapat dipastikan bahwa bank dengan total aset yang besar akan mampu memperoleh margin yang besar pula.

\section{Pengembangan Hipotesis}

\section{Pengaruh Manajemen Gap Terhadap Net Interest Margin (NIM)}

Manajemen gap merupakan sebuah stategi untuk memaksimalkan Net Interest Margin (NIM) melalui siklus margin atau bagi hasil. Jika manajemen memperkirakan tingkat bunga akan turun, posisi negatif gap akan menguntungkan. Sebaliknya pada posisi positif gap, kecenderungan turunnya tingkat bunga tidak menguntungkan. Oleh karena itu sebelum tingkat bunga benar-benar turun, manajemen segera memperkecil fund gap positif itu hingga mendekati nol atau bahkan menjadi negatif. Sebaliknya, bila tingkat bunga cenderung naik, manajemen akan mengusahakan posisinya menjadi positif. Dalam penelitian (Yunianti, 2019) menyebutkan bahwa manajemen gap berpengaruh positif terhadap net profit margin menunjukkan tetap terpeliharanya kepercayaan nasabah.

$\mathrm{H}_{1}=$ Manajemen Gap Berpengaruh Positif Terhadap Net Interest Margin (NIM).

\section{Pengaruh Modal Terhadap Net Interest Margin (NIM)}

Capital Adequacy Ratio (CAR) adalah kebutuhan modal dihitung berdasarkan Aktiva Terhitung Menurut Resiko (ATMR). Jika bank memiliki nilai CAR yang tinggi maka bank tersebut dapat meminimalisir untuk menutupi risiko kredit yang ada dengan itu dapat meningkatkan pendapatan bunga bersih Net Interest Margin (NIM). Berdasarkan penelitian dari (Nugrahaning, 2016) CAR berpengaruh positif terhadap Net Interest Margin (NIM).

$\mathrm{H}_{2}=$ Modal berpengaruh positif terhadap Net Interest Margin (NIM).

\section{Pengaruh Likuiditas Terhadap Net Interest Margin (NIM)}

Likuiditas merupakan ukuran kemampuan bank untuk membayar kembali seluruh kewajiban lancarnya. Risiko likuiditas terjadi jika bank tidak mempunyai likuiditas 
322 Inna Cikita Mahdatika \& Atina Shofawati, PENGARUH MANAJEMEN GAP, MODAL, LIKUIDITAS, RISIKO

yang cukup untuk memenuhi kewajiban jangka pendek secara tepat waktu. Maka likuiditas berhubungan positif terhadap Net Interest Margin (NIM). Menurut (Hidayat, 2019) ketika risiko likuiditas meningkat (yaitu rasio likuiditas menurun), bank kemungkinan akan meningkatkan suku bunga pinjaman mereka untuk mengurangi permintaan kredit, karena ketika bank memberikan lebih banyak pinjaman maka akan membuat likuiditas bank semakin rendah.

$\mathrm{H}_{3}=$ Likuiditas Berpengaruh Positif Terhadap Net Interest Margin (NIM).

\section{Pengaruh Risiko Pembiayaan Terhadap Net Interest Margin (NIM)}

Net Interest Margin (NIM) yang besar bagus untuk pertumbuhan perbankan namun hal ini akan membebani debitur yang akan membayar pinjaman yang tinggi, sehingga hal ini akan berdampak pada kemungkinan resiko gagal bayar. Dalam penelitian (Aryani, 2016) Net Interest Margin (NIM) mempunyai pengaruh signifikan terhadap volume NPF pada Bank Umum Syariah, selain itu pada penelitian (Entrop et al., 2015) juga ditemukan bahwa resiko kredit memiliki pengaruh positif terhadap NIM.

$\mathrm{H}_{4}=$ Risiko Pembiayaan Berpengaruh Positif Terhadap Net Interest Margin (NIM)

\section{Pengaruh Tingkat Efisiensi Terhadap Net Interest Margin (NIM)}

BOPO adalah rasio yang biasa digunakan untuk menentukan efisiensi sebuah bank. Jika nilai BOPO meningkat dapat dikatakan kinerja bank menurun. Semakin kecil nilai BOPO semakin bagus efisiensi sebuah bank. Karena semakin banyak dana tersalur oleh bank melalui pemberian kredit, maka margin akan meningkat sehingga memperbesar spread bunga yang berdampak pada penigkatan Net Interest Margin (NIM). Dalam penelitian (Dewi, 2017) menunjukkan bahwa BOPO berpengaruh positif signifikan terhdap NIM.

$\mathrm{H}_{5}=$ Tingkat Efisiensi Berpengaruh Positif Terhadap Net Interest Margin (NIM)

\section{Pengaruh Ukuran Bank Terhadap Net Interest Margin (NIM)}


ISLAMIC BANKING: Jurnal Pemikiran dan Pengembangan Perbankan Syariah, Volume 7 Nomor 2 Edisi Februari 2022

Menurut (Ugur, 2010) bahwa bank akan menerapkan margin yang tinggi dalam rangka untuk mengkompensasi risiko. Semakin besar size bank, maka akan semakin besar risiko yang akan ditimbulkan. Karena risiko yang besar dapat mempengaruhi sebuah bank untuk menerapkan tingkat margin yang tinggi. Dalam penelitiannya, diperoleh kesimpulan bahwa bank size berpengaruh positif terhadap Net Interest Margin (NIM).

$\mathrm{H}_{6}=$ Ukuran Bank Berpengaruh Positif Terhadap Net Interest Margin (NIM).

\section{Kerangka Pemikiran}

\section{Gambar 1}

Kerangka Konseptual Pengaruh Manajemen Gap, Modal, Likuiditas, Risiko

Pembiayaan, Tingkat Efisiensi dan Ukuran Bank Terhadap Net Interest Margin

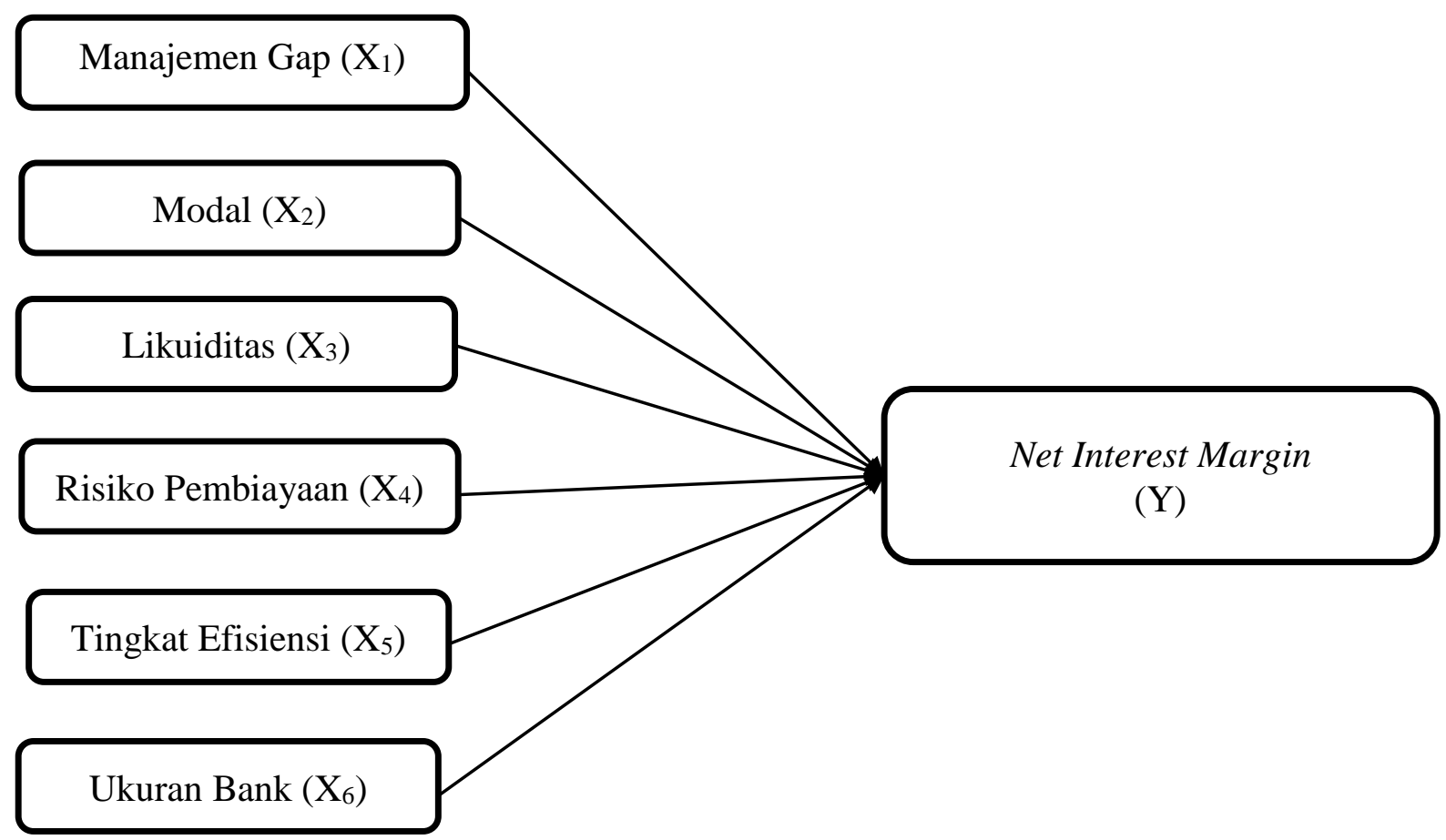

Metode Penelitian

Tabel 2

Definisi Operasional Variabel 
324 Inna Cikita Mahdatika \& Atina Shofawati, PENGARUH MANAJEMEN GAP, MODAL, LIKUIDITAS, RISIKO

\begin{tabular}{|c|c|c|}
\hline Variabel & Definisi & Formula \\
\hline Net Interest Margin & $\begin{array}{l}\text { Rasio yang digunakan untuk } \\
\text { menunjukkan kemampuan manajemen } \\
\text { bank dalam mengelola aktiva } \\
\text { produktifnya untuk menghasilkan } \\
\text { pendapatan bunga bersih. }\end{array}$ & $\begin{array}{l}\mathrm{NIM}= \\
\frac{\text { pendapatan bunga bersih }}{\text { aktiva produktif }} \times 100 \%\end{array}$ \\
\hline Manajemen Gap & $\begin{array}{l}\text { Pengaturan gap yang disebabkan oleh } \\
\text { tingkat deegre of sensitivitas dari } \\
\text { masing-masing pos aset maupun } \\
\text { masing-masing pos liabilitas yang } \\
\text { berbeda-beda. }\end{array}$ & $\begin{array}{l}\mathrm{GAP}= \\
\text { Rate Sensitive Asset (RSA) - } \\
\text { Rate Sensitive Liability (RSL) }\end{array}$ \\
\hline Modal & $\begin{array}{l}\text { Sekumpulan uang atau barang yang } \\
\text { digunakan sebagai dasar pelaksanaan } \\
\text { suatu pekerjaan. }\end{array}$ & $\begin{array}{l}\mathrm{EA}= \\
\frac{\text { ekuitas }}{\text { total asset }} \times 100 \%\end{array}$ \\
\hline Likuiditas & $\begin{array}{l}\text { Ukuran kemampuan bank untuk } \\
\text { membayar kembali seluruh kewajiban } \\
\text { lancarnya. }\end{array}$ & $\begin{array}{l}\mathrm{FDR}= \\
\frac{\text { total loan }}{\text { total } D P K} \times 100 \%\end{array}$ \\
\hline Risiko Pembiayaan & $\begin{array}{l}\text { Risiko yang muncul jika bank tidak } \\
\text { bisa memperoleh kembali cicilan } \\
\text { pokok dana atau bunga dari pinjaman } \\
\text { yang diberikannya atau investasi yang } \\
\text { sedang dilakukannya. }\end{array}$ & $\begin{array}{l}\mathrm{NPF}= \\
\frac{\text { total default loan }}{\text { total loan }} \times 100 \%\end{array}$ \\
\hline Tingkat Efisiensi & $\begin{array}{l}\text { Parameter yang sering digunakan } \\
\text { untuk mengukur kinerja organisasi. }\end{array}$ & $\begin{array}{l}\mathrm{BOPO}= \\
\frac{\text { operating expenses }}{\text { operating income }} \times 100 \%\end{array}$ \\
\hline Bank Size & $\begin{array}{l}\text { Suatu skala yang dapat } \\
\text { mengelompokkan besar kecilnya suatu } \\
\text { perusahaan. }\end{array}$ & $\begin{array}{l}\text { Bank Size }= \\
\text { Ln (Total Asset) }\end{array}$ \\
\hline
\end{tabular}

\section{Data}


ISLAMIC BANKING: Jurnal Pemikiran dan Pengembangan Perbankan Syariah, Volume 7 Nomor 2 Edisi Februari 2022

Penelitian ini menggunakan data panel dari tiga Bank Syariah yang merupakan anak usaha BUMN yakni PT. Bank Syariah Mandiri Tbk, PT. Bank BNI Syariah Tbk, PT. BRI Syariah Tbk. Penelitian ini menggunakan laporan keuangan triwulan dari tahun 2015 - 2019, sehingga observasi pada data ini berjumlah 60 .

\section{Metode}

Penelitian ini menggunakan metode kuantitatif, yaitu akan menguji variabel endogen dan eksogen dengan regresi data panel. Penelitian ini akan menguji korelasi antara variabel eksogen dan variabel endogen, yaitu variabel eksogen meliputi manajemen gap, modal, likuiditas, risiko pembiayaan, tingkat efisiensi dan ukuran bank (size), sedangkan variabel endogen meliputi Net Interest Margin.

Dalam anlisis data panel terdapat 3 pilihan model estimasi yang dapat dilakukan yaitu: Common Effect, Fixed Effect dan Random Effect. Istilah Fixed Effect adalah karena meskipun intersep berbeda-beda untuk tiap-tiap subjek, tetapi tiap intersep tidak berubah seiring waktu, inilah yang disebut sebagai time invariant. Pada model Fixed Effect Model (FEM), koefisien (slope) dari variabel independen tidak bebeda untuk setiap individu atau antar waktu. Pada Random Effect Model (REM) penentuan intercept $(\alpha)$ dan slope $(\beta)$ pada model ini di dasarkan pada asumsi bahwa intercept $(\alpha)$ terdistribusi secara random antar unit $\mu_{i}$ (Gujarati, 2012).

Estimasi model yang pada metode data panel digunakan untuk mendapatkan model terbaik dalam menganalisis pengaruh manajemen gap, modal, likuiditas, risiko pembiayaan, tingkat efisiensi dan ukuran bank (size) terhadap Net Interest Margin, adalah sebagai berikut:

$\mathrm{NIM}_{\mathrm{it}}=\alpha+\beta_{1}$ Manajemen Gapit $+\beta_{2}$ Modal $_{i t}+\beta_{3}$ Likuiditasit $+\beta_{4}$ Risiko Pembiayaan $_{i t}+\beta_{5}$ Tingkat Efisiensi $i t+\beta_{6}$ Bank Size $_{i t}+e$

Keterangan :

$\alpha=$ Konstanta

$\beta_{1}-\beta_{6}=$ Slope

e Error 
326 Inna Cikita Mahdatika \& Atina Shofawati, PENGARUH MANAJEMEN GAP, MODAL, LIKUIDITAS, RISIKO

\section{Pembahasan}

Berdasarkan hasil interpretasi pengolahan data menggunakan aplikasi eviews 9, didapatkan hasil pengujian data menggunakan Uji Chow dan Uji Hausman sebagai berikut:

Tabel 3

Uji Chow dan Uji Hausman

\begin{tabular}{|l|c|l|}
\hline \multicolumn{1}{|c|}{ Test Type } & Probabilitas & \multicolumn{1}{|c|}{ Hasil Hipotesis } \\
\hline Uji Chow & 0.0000 & $\begin{array}{l}\text { Tolak } \mathrm{H}_{1}, \mathrm{H}_{0} \text { diterima maka } \\
\text { menggunakan permodelan REM }\end{array}$ \\
\hline Uji Hausman & 1.0000 & $\begin{array}{l}\text { Tolak } \mathrm{H}_{1}, \mathrm{H}_{0} \text { diterima maka } \\
\text { menggunakan permodelan REM }\end{array}$ \\
\hline
\end{tabular}

Sumber: Hasil Uji Eviews 9

Nilai probabilitas yang diperoleh pada Uji Chow di tabel 3 sebesar 0.0000, hasil tersebut kurang dari taraf nyata yang digunakan dalam penelitian ini sebesar 5\% maka cukup bukti untuk menolak $\mathrm{H}_{1}$. Berdasarkan hasil uji tersebut menunjukkan bahwa model Random Effect Model diterima. Selanjutnya, hasil uji Hausman menunjukkan nilai probabilitas 1.0000 , nilai probabilitas tersebut lebih besar dari taraf 5\% sehingga cukup bukti untuk menolak hipotesis $\mathrm{H}_{1}$. Keputusan Uji Chow dan Uji Hausman menunjukkan bahwa model Random Effect Model merupakan pendekatan terbaik dalam penelitian ini.

\section{Tabel 4}

Hasil Regresi Data Panel Least Square

\begin{tabular}{|ccccc|}
\hline \hline Variable & Coefficient & Std. Error & t-Statistic & Prob. \\
\hline \hline C & 14.88406 & 5.881440 & 2.530683 & 0.0145 \\
MANAJEMEN_GAP & $4.31 \mathrm{E}-08$ & $1.42 \mathrm{E}-08$ & 3.040444 & 0.0037 \\
MODAL & -0.064921 & 0.013029 & -4.982674 & 0.0000 \\
FDR & 0.022537 & 0.008376 & 2.690648 & 0.0096 \\
NPF & -0.069506 & 0.056881 & -1.221968 & 0.2273
\end{tabular}


ISLAMIC BANKING: Jurnal Pemikiran dan Pengembangan Perbankan Syariah, Volume 7 Nomor 2 Edisi Februari 2022

\begin{tabular}{|lllll|}
\multicolumn{1}{|c}{ BOPO } & 0.021214 & 0.014060 & 1.508804 & 0.1375 \\
LN_BANKSIZE & -0.612380 & 0.290498 & -2.108037 & 0.0400 \\
\hline \hline & Effects Specification & \\
\hline \hline Cross-section fixed (dummy variables) & \\
\hline \hline R-squared & 0.939694 & Mean dependent var & 6.688167 \\
Adjusted R-squared & 0.930234 & S.D. dependent var & 0.903216 \\
S.E. of regression & 0.238569 & Akaike info criterion & 0.109164 \\
Sum squared resid & 2.902671 & Schwarz criterion & 0.423316 \\
Log likelihood & 5.725083 & Hannan-Quinn criter. & 0.232046 \\
F-statistic & 99.33526 & Durbin-Watson stat & 1.522045 \\
Prob(F-statistic) & 0.000000 & & \\
\hline \hline
\end{tabular}

Sumber: Hasil Uji Eviews 9

Berdasarkan pada tabel 4 diatas, bahwasannya $\mathrm{R}^{2}$ sebesar 0.939694 hal ini menunjukkan bahwa variasi model endogen pada Net Interest Margin dapat dijelaskan oleh variabel-variabel eksogen Manajemen Gap, Modal, FDR, NPF, BOPO, dan Bank Size sebesar $93 \%$ dan sisanya $7 \%$ dipengaruhi oleh variabel lainnya, diluar variabel eksogen yang digunakan dalam penelitian ini.

Pada tabel 4 yang merupakan hasil dari Regresi Data Panel Least Square, menyatakan bahwa variabel Manajemen Gap berpengaruh positif signifikan dengan Net Interest Margin. Dilihat dari nilai probabilitasnya $0.0037<0.05$ dengan nilai t-statistik 3.040444, maka dinyatakan bahwa $\mathrm{H}_{1}$ diterima, Manajemen Gap berpengaruh positif signifikan terhadap Net Interest Margin. Dalam hasil temuan ini telah sesuai dengan hipotesis dalam penelitian yang dilakukan oleh (Yunianti, 2019) yang menyatakan bahwa gap berpengaruh positif terhadap Net Interest Margin bank syariah. manajemen gap bertujuan untuk mempersempit lebarnya kesenjangan antara Rate Sensitive Asset (RSA) dan Rate Sensitive Liability (RSL). Kesenjangan yang terjadi di bank baik secara negatif jika jumlah liabilitas yang sensitif melebihi aset yang sensitif. Sebaliknya bila aset yang sensitif melebihi liabilitas yang sensitif, akan terjadi kesenjangan dana yang 
328 Inna Cikita Mahdatika \& Atina Shofawati, PENGARUH MANAJEMEN GAP, MODAL, LIKUIDITAS, RISIKO

positif. Dengan kesenjangan dana yang negatif, Net Interest Margin akan menurun jika tingkat bunga jangka pendek naik, sebaliknya Net Interest Margin akan naik bila tingkat suku bunga jangka pendek turun. Dalam keadaan kesenjangan positif maka dengan menurunkan tingkat bunga akan mengurangi tekanan atas Net Interest Margin (Darmawi, 2012).

Variabel Modal menunjukkan bahwa nilai probabilitasnya sebesar $0.0000<0.05$ dengan nilai t-statistik -4.982674 dapat disimpulkan bahwa $\mathrm{H}_{2}$ diterima, Modal berpengaruh negatif signifikan terhadap Net Interest Margin. Setiap Modal meningkat 1 persen maka akan menurunkan Net Interest Margin sebesar 0.06\%. Hal ini diperkuat oleh penelitian (Almunawaroh, 2018), (Dewi, 2017) yang menyatakan bahwa rasio modal berpengaruh positif terhadap Net Interest Margin. Nilai rasio modal pada Bank Mandiri Syariah, Bank BRI Syariah, Bank BNI Syariah menyebabkan penurunan pada Net Interest Margin. Hal ini dikarenakan Net Interest Margin adalah pendapatan bunga bersih dengan rata-rata aktiva produktif yang dimiliki oleh bank, rasio ini menunjukkan kemampuan manajemen bank dalam mengelola aktiva produktifnya untuk menghasilkan bunga bersih. Sedangkan modal bukan termasuk dalam aktiva produktif.

Variabel Likuiditas yang diukur menggunakan rasio FDR menunjukkan bahwa nilai probabilitasnya sbesar $0.0096<0.05$ dengan nilai t-statistik 2.690648 dapat disimpulkan bahwa $\mathrm{H}_{3}$ diterima, FDR berpengaruh positif signifikan terhadap Net Interest Margin. Maka setiap FDR naik 1 persen akan menaikkan Net Interest Margin sebesar 0,02\%. Hal ini sejalan dengan peneitian yang dilakukan oleh (Dewi, 2017) yang menyatakan bahwasannya LDR berpengaruh positif terhadap Net Interest Margin. Hal ini menunjukkan semakin besar rasio likuiditas yang berarti rendahnya likuiditas bank akan meningkatkan Net Interest Margin. Jika rasio tinggi mengindikasikan sedikitnya dana yang tersimpan secara likuid dan meningkatkan dana yang disalurkan dalam bentuk pembiayaan sehingga ketika kewajiban jangka pendek bisa dibayarkan dengan pembiayaan maka keuntungan yang diperoleh bank dari hasil pembiataan pun akan semakin meningkat dan diindikasikan dengan peningkatan nilai Net Interest Margin.

Variabel Risiko Pembiayaan yang diukur menggunakan rasio NPF menunjukkan bahwa nilai probabilitasnya sebesar $0.2273>0.05$ dengan nilai t-statistik -1.221968 
ISLAMIC BANKING: Jurnal Pemikiran dan Pengembangan Perbankan Syariah, Volume 7 Nomor 2 Edisi Februari 2022

dapat disimpulkan bahwa $\mathrm{H}_{4}$ ditolak, yang berarti bahwa NPF tidak berpengaruh terhadap Net Interest Margin. Hal ini diperkuat dengan penelitian yang dilakukan oleh (Arif, 2018) mengindikasikan bahwa besarnya Net Interest Margin pada bank yang masuk kategori buku I dan buku IV tidak dipengaruhi oleh tingkat risiko kredit atau pembiayaan. Ketika bank berada dalam kondisi dengan tingkat risiko kredit atau pembiayaan yang tinggi maka akan cenderung mengambil kebijakan untuk meminimalisasi risiko dalam menghasilkan keuntungan yang tinggi, namun kebijakan ini tidak terlalu berdampak signifikan terhadap peningkatan margin.

Variabel Tingkat Efisiensi yang diukur menggunakan BOPO menunjukkan bahwa nilai probabilitasnya sebesar $0.1375>0.05$ dengan nilai t-statistik 1.508804 dapat disimpulkan bahwa $\mathrm{H}_{5}$ ditolak, yang berarti bahwa BOPO tidak berpengaruh terhadap Net Interest Margin. Hasil penelitian ini sejalan dengan penelitian yang dilakukan oleh (Iloska, 2014) bahwa nilai BOPO sangat tinggi sementara rasio NIM rendah sehingga membuat variabel BOPO tidak memberikan pengaruh yang signifikan. Penelitian ini juga bertolak belakang dengan penelitian yang dilakukan Entrop et al. (2015) yang menemukan bahwa biaya operasional memiliki koefisien negatif terhadap NIM. BOPO mencerminkan kurangnya peningkatan kemampuan bank untuk mengurangi biaya operasi dan meningkatkan pendapatan operasional yang mengakibatkan kerugian apabila bank kurang efisien dalam mengelola BOPO sehingga dapat menyebabkan penurunan pada Net Interest Margin pada Bank Syariah.

Variabel Ukuran Perusahaan (Bank Size) menunjukkan bahwa nilai probabilitasnya sebesar $0.0400<0.05$ dengan nilai t-statistik -2.108037 dapat disimpulkan bahwa $\mathrm{H}_{6}$ diterima, FDR berpengaruh negatif signifikan terhadap Net Interest Margin. Berdasarkan hasil penelitian ini, tidak sejalan dengan penelitian yang dilakukan (Dewi, 2017) menunjukkan penerimaan atas hipotesis Bank Size berpengaruh positif signifikan terhadap Net Interest Margin namun penelitian ini mendukung penelitian Kumar et al., (2020) yang menyebutkan bahwa ukuran bank memberikan dampak negatif terhadap profitabilitas, namun memang secara umum ketidakkonsistenan hasil-hasil penelitian mengenai pengaruh ukuran bank terhadap pertumbuhan bank perlu dianalisis secara lebih mendalam. Pada umumnya, semakin 
330 Inna Cikita Mahdatika \& Atina Shofawati, PENGARUH MANAJEMEN GAP, MODAL, LIKUIDITAS, RISIKO

besar ukuran bank akan berdampak pasa skala ekonomi dan pengurangan biaya atau economies of scope, dan diversifikasi produk yang ditawarkan bank dan menyediakan akses pada pasar yang tidak dapat diakses oleh bank-bank kecil. Sebagai tambahan, bank besar dapat memperkuat pangsa pasar melalui penguatan brand image atau perlindungan regulasi secara implisit (Iloska, 2014), Tariq (2014) juga mengatakan bahwa Bank Size berpengaruh signifikan terhadap Net Interest Margin.

\section{Simpulan}

Hasil penelitian menunjukkan bahwa secara simultan seluruh variabel eksogen (Manajemen Gap, Modal, Likuiditas, Risiko Pembiayaan, Tingkat Efisiensi, Bank Size) berpengaruh signifikan terhadap variabel endogen (Net Interest Margin). Secara parsial variabel Manajemen Gap dan Likuiditas berpengaruh positif signifikan terhadap Net Interest Margin. Sedangkan variabel Modal dan Bank Size berpengaruh negatif signifikan terhadap Net Interest Margin. Namun pada variabel Resiko Pembiayaan dan Tingkat efisiensi tidak berpengaruh secara signifikan terhadap Net Interest Margin pada PT. Bank Syariah Mandiri Tbk, PT. Bank BNI Syariah Tbk, PT. BRI Syariah Tbk. Nilai $\mathrm{R}^{2}$ didapatkan hasil sebesar 0.939694 hal ini menunjukkan bahwa variasi model endogen pada Net Interest Margin dapat dijelaskan oleh variabel-variabel eksogen Manajemen Gap, Modal, Likuiditas, Resiko Pembiayaan, Tingkat Efisiensi, dan Bank Size sebesar $93 \%$ dan sisanya $7 \%$ dipengaruhi oleh variabel lainnya, diluar variabel eksogen yang digunakan dalam penelitian ini.

Penelitian ini masih terbatas, karena sampel yang digunakan hanya pada PT. Bank Syariah Mandiri Tbk, PT. Bank BNI Syariah Tbk, PT. BRI Syariah Tbk tidak keseluruhan Bank Syariah di Indonesia. Net Interest Margin yang digunakan masih belum semua digunakan dalam variabel eksogen seperti Inflasi, BI Rate, dan lain sebagainya. Penelitian selanjutnya diharapkan dapat menambah variabel yang lainnya selain yang telah penulis sebutkan dalam penelitian. 
ISLAMIC BANKING: Jurnal Pemikiran dan Pengembangan Perbankan Syariah, Volume 7 Nomor 2 Edisi Februari 2022

\section{DAFTAR PUSTAKA}

Almunawaroh, M. D. (2018). Faktor-Faktor yang Mempengaruhi Profitabilitas Ban. Etinomika, 14(2).

Arif, A. (2018). Pengaruh Resiko Kredit dan Ukuran Perusahaan Terhadap Net Interest Margin (NIM) di Sektor Perbankan. Jurnal Informasi Perpajakan, Akuntansi Dan Keuangan Publik, 13(1), 1-14.

Aryani, Y. L. (2016). Faktor-Faktor yang Mempengaruhi Non Performing Financing pada Bank Umum Syariah Indonesia Periode 2010-2014. Al-Muzara'ah, 4(1).

Askarullah, M. W. (2017). Perbandingan Pembentukan Gab Sensitivitas Pada Bank Syariah Mandiri dan Bank Mega Periode 2011-2015. Jurnal Ekonomi Syariah Teori Dan Terapan, 4(8).

Astohar, S. R. (2019). Faktor yang Berpengaruh Terhadap Profitabilitas dengan Net Interest Margin sebagai Variabel Intervening pada Bank Perkreditan Rakyat. Among Makarti, 12(24).

Darmawi, H. (2012). Manajemen Perbankan. Jakarta: Bumi Aksara.

Dewi, I. L. (2017). Pengaruh Faktor Internal dan Eksternal Bank Terhadap Net Interest Margin di Indonesia. E-Jurnal Manajemen Unud, 6(6).

Entrop, O., Memmel, C., Ruprecht, B., \& Wilkens, M. (2015). Determinants of bank interest margins: Impact of maturity transformation. Journal of Banking and Finance, 54, 1-19. https://doi.org/10.1016/j.jbankfin.2014.12.001

Gujarati. (2012). Dasar-Dasar Ekonometrik. Jakarta: Salemba Empat.

Hidayat, A. A. (2019). Pengaruh Risiko Kredit dan Risiko Likuiditas Terhadap Net Interest Margin sesuai Pertumbuhan Ekonomi pada Bank Umum di Indonesia Periode 2010-2017. Jurnal Manajemen Dan Bisnis Sriwijaya (JMBS), 17(2).

Iloska, N. (2014). Determinants of Net Interest Margin - The Case of Macedonia. Journal of Applied Economics and Bussiness, 2(2), 17-36.

Islam, M. S., \& Nishiyama, S. I. (2016). The determinants of bank net interest margins: A panel evidence from South Asian countries. Research in International Business and Finance, 37, 501-514. https://doi.org/10.1016/j.ribaf.2016.01.024

Kumar, V., Acharya, S., \& Ho, L. T. H. (2020). Does monetary policy influence the profitability of banks in new zealand? International Journal of Financial Studies, 8(2), 1-17. https://doi.org/10.3390/ijfs8020035

Nugrahaning, S. D. (2016). Analisis Pengaruh NPL dan LDR terhadap NIM dengan ROA sebagai Variabel Intervening, Pengaruh NPL terhadap NIM dengan CAR dan ROA sebagai Intervening, serta BOPO terhadap NIM Bank Go Public di 
332 Inna Cikita Mahdatika \& Atina Shofawati, PENGARUH MANAJEMEN GAP, MODAL, LIKUIDITAS, RISIKO

Indonesia Periode 2011-2015. Journal of Management, 5(4).

Riyadi, S. (2006). Banking Aset and Liablitiy management. Jakarta: Lembaga Penerbit Fakultas Ekonomi Universitas Indonesia.

Saksonova, S. (2014). The Role of Net Interest Margin in Improving Banks' Asset Structure and Assessing the Stability and Efficiency of their Operations. Procedia - Social and Behavioral Sciences, 150, 132-141. https://doi.org/10.1016/j.sbspro.2014.09.017

Tariq, W. D. (2014). Determinants of the Commercial Banks Profitability: Empirical Evidence From Pakistan. International Journal of Accounting and Financial Reporting, 4(2), 1-22.

Ugur, A. D. (2010). Determinants of the Net Interest Margins of Banks in Turkey. Jurnal of Economic and Social Research, 12(2).

Yunianti, L. D. (2019). Pengaruh Manajemen Gap pada Assets and Liability Management. Prosiding Manajemen, 5(1). 